Terbit online pada laman web jurnal : http://e-journal.sastra-unes.com/index.php/JILP

\begin{tabular}{|c|c|c|}
\hline \multirow[b]{2}{*}{$\begin{array}{c}\text { Fakultas Sastra } \\
\text { Universitas Ekasakti }\end{array}$} & \multicolumn{2}{|c|}{$\begin{array}{c}\text { (JURNAL, ILMIAH LANGUE AND PAROLE) } \\
\text { VOLUME } 2 \text { NOMOR } 2\end{array}$} \\
\hline & $\begin{array}{c}\text { ISSN : 2581-0804 } \\
\text { (Media Cetak) }\end{array}$ & $\begin{array}{c}\text { E-ISSN : 2581-1819 } \\
\text { (Media Online) }\end{array}$ \\
\hline
\end{tabular}

\title{
SEMIOLOGY ANALYSIS ON SIKEREI TATTOO IN TAILELEU VILLAGE, SOUTHWEST SIBERUT, MENTAWAI ISLAND
}

\author{
Rosli Penji Sagugurat, Mac Aditiawarman \\ Fakultas Sastra Universitas Ekasakti \\ roslipenji94@gmail.com, mac_aditiawarman@yahoo.com
*Corresponding Author: Mac Aditiawarman
Fakultas Sastra Universitas Ekasakti mac_aditiawarman@yahoo.com

\begin{abstract}
This research is entitled "Semiology Analysis on Sikerei Tattoo in Taileleu village, southwest Siberut, Mentawai Island" seen from the perspective of structuralism. This research is limited to a number of basic ideas relating to observations into the following three questions: (1) how the forms of Sikerei tattoo, (2) what the meaning of Sikerei tattoos, and (3) what the function of Sikerei tattoo. The objectives of this research were (1) to explain the forms of Sikerei tattoo, (2) to analyze the meaning of Sikerei tattoo, and (3) to describe the function of Sikerei tattoo. The theory used is from Pierce's about semiotics which is used to answer the purpose of this research. For the method of data analysis, the authors use qualitative research by emphasizing meaning and inner understanding (verstehen), reasoning, definitions of certain situations (in some contexts), more to examine things related to everyday life such as the culture of an area and also semiotic theory. Data collection techniques use literature study techniques in finding data that is relevant to the subject of analysis. This research is qualitative research using the form of field notes, interviews, official personal documents, and photographs or images. The object of this research is Sikerei who is tattooed and the data is tattoos. Finding in this analysis will be focused on the Sikerei tattoo in Taileleu village, southwest Siberut, Mentawai Island. First, the forms of Sikerei tattoo. Second, the meaning of Sikerei tattoo. Third, the function of Sikerei tattoo. Conclusion in this analysis is Sibalubalu as a symbol of health, said health because Sibalubalu is only used by Sikerei where Sikerei is a remedy for sick people in the Mentawai Islands especially in Taileleu village. And suggestion in this thesis is the early achievement that still needs to be developed and continued with more careful study, especially in terms of the research in the field of Sikerei tattoo.
\end{abstract}

Keywords Sikerei Tattoo, Sibalubalu Tattoo, Mentawai Tattoo

(C) 2019Jurnal JILP

Jurnal JILP (Jurnal Ilmiah Langue and Parole) Vol. 2 No. 2 (2019) ISSN : 2581-0804

This work is licensed under a Creative Commons Attribution-NonCommercial 4.0 International License. 


\section{INTRODUCTION}

Tattoos generally are art of tattooing with various objects as, images, symbols and writings, even replicas of photographs. The term "tattoo" is taken from the word "Tatau" in the Tahiti language that mean is sign.

According to Rosa (1994), Mentawai tattoo is the oldest tattoo in the world, known as Titi, a type of tattoo painted on the body of a Mentawai that fills the entire body, from head to toe.

According to Rosa (1994), Mentawai tattoo is the oldest tattoo in the world known as Titi, a type of tattoo painted on the body of a Mentawai that fills the entire body, from head to toe. The Mentawai tribe considers tattoos to be sacred and serves as a symbol of natural balance which is the spirit of life. William Marsden in his 18th century report said that the Mentawai population generally used tattoos (titi). They began giving tattoos to boys from the age of seven. The more the child gets older, the more tattoos are equipped.

Rosa (1994) estimates that there are around 160 traditional Mentawai tattoo motives, he concluded that Mentawai tattoos are closely related to Dongson culture in Vietnam, allegedly from there Mentawai originated. For mentawai people, tattoos are timeless clothes that can be carried to death, or in other words, the Mentawai tattoo tradition only becomes a work of art as long as humans use it live. There are even people who say that the Mentawai people tattoo their bodies so that later after death they can recognize each other's ancestors. Based on the Mentawai tradition, tattoos also have a function as a symbol of natural balance. In the Mentawai tradition objects such as stone, animals, and plants must be enshrined in their bodies because they think they all have souls.

Mentawai tattoos have various motives such as sunancura motives (deer), sakkokok (pigs), joja (apes) and so on that describe the hunt, and sibalubalu for sikerei (shaman) motives. There are also motives taken from the core of the animal's shape, such as the saggesaggei (crab) motive and the laita (fish) motive. Mentawai tattoos with various motives in the life order of the community, have a very important social function, namely as a visual language. Mentawai tattoo is a communication vehicle built through visual language, rich in thoughts and feelings. Each mentawai tattoo motive has the meaning of a password as a sign. Mentawai tattoo motives are a vehicle for visual language communication, essentially as a source of information about one's activities related to social problems.

This is shown by the users of Mentawai tattoos which contain symbolic elements, function as a sign of familiarity with the characteristics of each variety of motives, as well as their placement in each body part. The variety of Mentawai tattoo motives convey a different attitude, and describe the communicative needs of the Mentawai indigenous people in their existence as shamans and hunters. If the Mentawai tattoo is studied through literature which focuses more on written texts, the Mentawai tattoo motives also fulfill these requirements (Rosa: 2014). In the practice of literature the Mentawai tattoo motives are texts expressed through visual language, where traditional tattoo motives carried by the Mentawai indigenous people also have pragmatics, as language is used in certain social contexts. In conjunction with visual language through Mentawai tattoo motives, syntax can be shown on tattoo motives as texts that indicate anaphoric, such as Mentawai Sibalubalu tattoo motives showing the position of Sikerei (shaman) to the same person has a predicate (Rosa: 2014).

Tattoo motives as text are a unity in the expression of visual language as communication used within the scope of the Mentawai indigenous community. In addition to pragmatics and sintatics, the semantic unity demanded as a text is a global theme that encompasses all elements. Semantics that can be related to the diversity of tattoo motives as text in visual languages, namely when looking at the structure of a text that has proximity to the pragmatic and syntactic elements found in the body of a tattoo user. Textual means the factual, which is a fact that relates to the structure of society, which has a position as a form of information based on objective reality.

When viewed from the interaction theory, as stated Veeger (1993: 133) see Society as a dynamic process, where humans are actors and 
responsible, want to unite individual aspects and social aspects into one and the same life. To unite these communities must have a system, one of which is to use visual language through a variety of tattoo motives that are used as text as a source of information relating to the structure of life of indigenous peoples. Tattoos are the spirit of life for people who Mentawai where one position is to show the identity of the tattoo and differences in social status or profession. For example the Sikerei tattoo (the name for the Mentawai shaman) is different from the tattoo hunter. Hunters are known as pictures of their catches such as pigs, deer, monkeys, birds, or crocodiles while Sikerei is known from the stars of the Sibalubalu tattoo on their bodies.

Rosa (1995:107) the formation of symbols because of the relationship between the philosophies of life of the Mentawai indigenous people formulated through conventions, including can be expressed through visual forms. The condition of these indigenous peoples, according to Bouman (1954: 131) 'is the easiest to be given a sociological interpretation, because it expresses group feelings in a real way for collectivity. The meaning of Mentawai tattoo has strong ties with the standard rules that apply in the order of the Mentawai indigenous people, various forms and patterns of tattoo motives are used as rules and laws based on the Mentawai indigenous people's beliefs. The meaning of tattoos through a variety of motives is nothing but the visual language, through the symbol of the signaling system, used as a vehicle of communication conveyed through forms of tattoo motives. Still related to visual language, Tabrani (in Rosa 1994) suggests that in the language of words, each ethnic group has different words to designate the same object. In language studies, words are tribes which create what words to refer to the same object and what meaning and development / change in meaning.

Based on this fact, the role of visual language, through the variety of tattoo motives as a medium of communication, has a huge influence on the lives of the Mentawai indigenous people. The form of traditional tattoo motifs has meaning-messages, namely the thoughts and feelings of the source as outlined in the form of tattoo motives that can be perceived by the senses (sight). The shape of the tattoo motive on the body of the Mentawai indigenous people has certain meanings, according to the meaning and each meaning of the tattoo motive. Used of the traditional tattoo motives in Mentawai indigenous people as visual languages, the main purpose of which is as a vehicle of communication. The each tattoo motive has a meaning that is used by ethnic ( Mentawai ), based on communal agreement. According to Sakri (1989), the element of information must be valid. It can be done by sending and receiving messages, whether intentional or not. The message is sent by the source and received by the recipient.

The traditional tattoo motives of the Mentawai indigenous people have meaningmessages in standard information communication, therefore among the Mentawai indigenous people tattoo wearers have shown the existence of elements of collusion. They send and receive messages through the traditional tribe institutions of the Mentawai indigenous people which are made into life based on the convention. Tattoos with a variety of motives are a sign of the appearance of traditional cultural activities, have long existed in the Mentawai indigenous community. The diversity of Mentawai tattoo motives is a collection of sign elements as a means of communication. This happened because they did not know the written language. Tattoos with various motives are the management of communication vehicles called visual languages. Based on empirical perceptions, it is thought that the visual language through mentawai tattoo motives is the initial language or commonly used, because it does not know the written language.

\section{RESEARCH METHOD}

The method used is Qualitative Research which aims to create a systematic, factual, and accurate picture of the social status of the follows:

The method used to collect data is as Sibalubalu Tattoo in Mentawai.

Jurnal JILP (Jurnal Ilmiah Langue and Parole) Vol. 2 No. 2 (2019) ISSN : 2581-0804

This work is licensed under a Creative Commons Attribution-NonCommercial 4.0 International License. 
Field research is collecting data by conducting research directly on the object of research through:

Interviews are question and answer activities to several parties, both Sikerei and people who have extensive knowledge about tattoos. Interviews are direct communication techniques between researchers and informants or conversations conducted by two parties, namely the interviewer (interviewer) who asks questions and the interviewee (interview) who provides answers to the question. The interview is a data collection technique that asks questions directly by the interviewer to the informant, and the questions are recorded and recorded. This interview is the main helper of the observation method, because by interviewing we can record vacancy data that cannot be recorded from observation. The interview technique is used to obtain more concrete information that cannot be done by observation, namely by meeting face to face with the informant.

Informants are people who provide information about the situation and background conditions of the study. The informant selection technique used in this research is the selection of informants with snowball sampling. Snowball sampling is a sampling technique for data sources, which are initially small in number, becoming large over time. This is done because a small number of data sources have not been able to provide complete data, then look for other people who can be used as data sources. In this research the research informants were sikerei or elder tattooed on the Mentawai Island. The number of informants in this research refers to the informant retrieval system in the principle of qualitative research, where the number of informants is not determined from the beginning of the study, but after the research is completed. Interviews will be stopped when the informant variation is not expected to be in the field and the data or information obtained through careful analysis illustrates the pattern of the problem being studied.

In this research, the technique used is an unstructured interview technique, meaning the interviewer is free to ask various questions to the informant and the informant is free to answer questions according to what they want, in this case the informant is free to express his feelings, thoughts, and views without asking questions
Intervention from researchers. The reason for using the structured interview technique is that the interview can be carried out freely and deeply which is done based on a guideline or note that contains thoughts in the form of in-depth questions that will be asked during the interview. This interview was carried out between the interviewer and the informant who was repeatedly carried out. Repeatedly does not mean repeating the same question, but asking different things and classifying the information that has been obtained previously.

When conducting an interview, the researcher first informs the informant of the purpose of the interview. After that, the interview begins by referring to the interview guidelines so that researchers can properly ask about things that are relevant to the research objectives. The interview itself was carried out after there was an agreement that the data obtained was only useful for the interests of research and privacy or the identity of the informant who knew nothing but the researcher.

Interviews with informants were carried out openly with a comfortable situation so that informants could answer questions at length about the problems that the researcher proposed. In this research, researchers used field notes written using a pen so that the results of interviews could be processed and then analyzed according to the purpose of the study. In addition, the camera was also used to take photos of informants while conducting interviews, and some photos from the research picture. This research used an interview method to look for data about Sibalubalu tattoo.

Observation is an activity of observation and recording carried out by researchers in order to perfect research in order to achieve maximum results. In this case the researcher makes a direct observation of the object under study in order to obtain the data needed and understand the actual activities that occur.

According to Nawawi and Martini (1992: 74), "Observation is the observation and recording systematically of the elements that appear in a symptom or symptoms in the object of research". Observations of researchers can find out the process of making tattoos for the Mentawai community.

The use of observations is: observation optimizing the ability of researchers in terms of 
motives, beliefs, attention, unconscious behavior, habits and so on. Observation allows observers to see the world as seen by the subject of research, living at that time, capturing the meaning of phenomena in terms of the subject, capturing cultural life in terms of the views and sequences of the subjects at that time. Observation allows researchers to feel what is felt and internalized by the subject so as to enable researchers to become sources of data; observation allows the formation of knowledge that is known to be shared, both from his side and from the subject. This research used an observation method to look for data about Sibalubalu tattoo.

Documentation is the collection of data by researchers by collecting data in the form of documents from trusted sources and records needed in research.

According to Arikunto (2006: 231), Documentation is to find data about variables in the form of notes, transcripts, books, newspapers, magazines, inscriptions, minutes of meetings, agendas and so on. While the documentation according to Sugiyono (2015: 329) is a method used to obtain data and information in the form of books, archives, documents, writing numbers and images in the form of reports and information that can support research. Documentation used to collect data is then reviewed.

Based on the two opinions of experts it can be concluded that data collection by means of documentation is something done by researchers to collect data from various things printed media will be investigated. This research uses the documentation method to look for data about Sibalubalu tattoo.

In this research, to obtain the data and information needed, researchers used a literature study method. Library methods or library studies are carried out by obtaining written data or information sourced from books and various articles in libraries which according to researchers can support this research. Literature studies are carried out by reading and studying other books or literature relating to discussion of problems as a theoretical basis and tools for conducting analysis. This research used the Library Study method to look for data about Sibalubalu tattoo.

To get more information about this research, the authors also access websites and sites that are related to the information needed. This research uses the Website and Site Access method to look for data about Sibalubalu tattoo.

In analyzing, the analysis of the research used is a qualitative approach. This approach emphasizes meaning and inner understanding (verstehen), reasoning, definitions of certain situations (in some contexts), more to examine things related to everyday life such as the culture of a region. The purpose of research is usually related to practical matters.

Data analysis is the process of organizing and sorting data into patterns, categories and units of basic description of the results of observations that have been written in the form of field notes, interviews, official personal documents, photos, pictures and so on. Data analysis is also a process of simplifying data into a form that is easier to read and interpreted to find broader meanings and implications of the results of research. All data obtained from the field through interviews and observations will be arranged systematically and then analyzed qualitatively, the implementation of which began to be carried out since data collection was done and done intensively, namely after leaving the field. Data obtained in the field is recorded in the field note. Then it is collected and studied as a whole that is then analyzed and the researcher must begin analyzing it during the research process.

The analysis in this research was to describe the reason for people tattooed in the Mentawai.

Analysis of data in qualitative research is an activity carried out continuously during the research takes place, carried out starting from data collection to the stage of report writing. Data analysis was carried out since going down to the research location, each data collected was transferred to the field notebook. Furthermore, it will be grouped and analyzed and interpreted.

Activities carried out by a researcher in analyzing data were carried out continuously during the research. Data analysis was carried out from the start of the study the end of the study, analyzed which starts from examining all available data from various sources, namely indepth interviews, observations and secondary data.

Research that uses this qualitative method will then use qualitative analysis. Analysis by 
making a description that is expected to be able to provide a concrete explanation of the problem under study. The researcher will concentrate during the research, in order to produce data that can truly be accounted for. By recording, the results of interviews and direct observation by focusing based on the designation of meaning (in the form of interpretation of field data).

Data analysis is carried out in stages and continuously, after the results of interviews and observations have been collected (in the form of field notes) it will be immediately written down and consulted with the supervisor from the results of the research obtained. Re-discuss the things that need to be done to get a more concrete explanation. This will be done continuously until the data you want to achieve is fulfilled.

The data generated will be arranged systematically, so that it can provide an overview of the conclusions of the study. This research used a qualitative approach to look for data on Sibalubalu tattoo.

In this research, to obtain the data and information needed, researchers used literature study techniques. In the literature study the researcher uses material or references that relate to the problem and research objectives. Data analysis in qualitative research means systematic testing of data to determine its parts, relationships between parts, and the relationship of parts to the whole, by categorizing data and finding relationships between categories. From some understanding of data analysis, researchers group data into certain groups and look for relationships between groups of data. This literature study method or literature is done by obtaining data or written information sourced from books and various articles which according to researchers can support this research. This research uses a literature study technique to look for data on Sibalubalu tattoo.

Data analysis is the process of systematically searching for and compiling data obtained from interviews, field notes, and documentation, by organizing data into categories, describing into units, synthesizing, arranging into patterns, choosing which ones are important and that will be studied, and make conclusions so that it is easily understood by oneself and others (Sugiyono, 2011: 333).

The data analysis technique used in this research is the interactive model of Miles and Huberman (1992: 16-20), which is an interactive model. This method classifies data analysis in three steps, namely:

Data reduction is defined as the selection process, focusing on simplifying, abstracting, and transforming "rough" data that appears from written records in the field. This research uses data reduction techniques to look for data about Sibalubalu tattoo

Presentation of data is namely a series of information organizations that allow research to be carried out. Presentation of data obtained by various types, networks, and relatedness activities. Presentation is a set of structured information that gives the possibility of drawing conclusions and taking action. This research uses data presentation techniques to look for data about Sibalubalu tattoo.

The third important analysis activity is drawing conclusions and verification. From the beginning of data collection, a qualitative analyzer begins to look for the meaning of objects noting order, patterns, explanations, possible configurations, causal paths, and propositions. After data collection is completed, it is continued with data reduction; the data obtained will be summarized, sorted and focused on important data.

After reducing and obtaining important data, the next step is to present the data. This step is done to make it easier for researchers to understand what is happening, to plan further work. The final step is to conclude or verify that is to find a description or description that did not exist before, or which was previously unclear becomes clear. This research uses conclusions / verification techniques to look for data about Sibalubalu tattoo. 


\section{RESULTS AND DISCUSSION}

Sibalubalu's motive has closeness to the prehistoric human conception, through its myths, among others, as expressed by Vredenberg (1981) that this creation myth is entirely sexual and conception. Indeed there is another version of the creation of nature once the main point has not changed, namely that the sun and stars (each symbol of men and women) are responsible for the creation of humans. 'Aside from being a symbol of fertility which is illustrated through Sibalubalu tattoo, it is aimed at women who are responsible for the development and survival of humans in the universe, it gives weight and responsibility on his shoulders. The placement of Sibalubalu for Sikerei motive is located at the base of the arm. Various images of Sibalubalu motives that are intended for Sikerei, each region has the same and some are different.

Sibalubalu tattoo is not only a symbol or a sign of being familiar with a Sikerei (Shaman), but also Sibalubalu tattoos are intended to beautify the body. Sibalubalu decorative variety as an element of beauty for women and prowess for men, has a wide spread that has similarities. That is, the ornamental variety of Sibalubalu found in the North Siberut region is also found in South Siberut. This is very difficult to trace, because each region claims that they first claimed to use the motive. Sibalubalu tattoo is one part of the Mentawai tattoo motive that has the highest position among other Mentawai tattoo motives. In the Taileleu area Sibalubalu tattoos are not located on the top of the shoulder, but are located on the arms and legs between the titi rere, which includes the silioi motive on the ankles and calves, and above the silioi motive there is a muriok sara motive up to the back.

\section{The forms of Sikerei tattoo}

The first point that the writer wants to analyze from this research is the forms of the Sikerei tattoo in Mentawai, especially in Taileleu village.

Sibalubalu tattoo which is star-shaped means a symbol of a shaman to maintain health or well-being within the indigenous community as found in the Taileleu community of the Mentawai Islands, the meaning contained in Sibalubalu tattoos as a symbol of shaman, Star motifs as symbols that have health guards in indigenous peoples Mentawai especially the Taileleu village.

Sibalubalu tattoo is a symbol of women as the person in charge and the survival of humans in the universe, giving weight and responsibility on his shoulders. Because humans are born through the mother's womb (female) symbolized by a star, then in the motifs there are also Sibalubalu tattoo, on the left and right sides of the shoulder, in each traditional Mentawai woman has this motif as well as a natural sign of women. In addition to the chest part known as Titi Dapdap, there are also other familiar signs which include tattoos on the arms, legs, face and stomach.

The traditional Mentawai community, especially Taileleu village, is not only men who have known signs through tattoos, but also women. However, in the village of Taileleu the motives for identifying women are not as many as men have in their type. The main sign of recognition for women is titi dapdap, tattoos found on the shoulder and chest, the tattoo is a tribal identity. This Titi dapdap implies symbolic meaning through the form of Sibalubalu on the shoulder.

In the Taileleu region, Sibalubalu tattoos are formed through titi dapdap that uses simpler lines, using only two main lines in the chest, then fused to the shoulder and forming Sibalubalu.

According to Sikerei Teteu Bautubu Sabalai, Sibalubalu tattoo is the rank of the Sikerei in the Taileleu village, but the placement of Sibalubalu is not the same between men and women. In order for the nature of women as human survival not to be considered low, Sibalubalu is placed on the shoulders.

Whereas for men who are concerned with the sense of responsibility of men towards the family, because it involves life necessities, namely fulfillment of protein, Sibalubalu is located in the hands and feet. Sibalubalu are lines that form stars. the motif in the hand has a close connection with what was revealed by Sikerei Teteu Bautubu Sabalai from the village of Taileleu, Soutwest Siberut, Sibalubalu located in the hands and feet. 


\section{The meaning of Sikerei Tattoo}

The second point of this analysis is the meaning of Sikerei tattoo in Mentawai, especially in Taileleu village.

According to research conducted in the field, the definition of Sibalubalu is very closely related to the Mentawai indigenous people's beliefs, especially in the Taileleu village.

The meaning of the word Sibalubalu comes from the word Balubalu which means eight-eight, which is a line that forms a star. Balubalu means a group of stars in the sky and when there are only eight stars in the sky. So the star for them has a special position among heavenly bodies.

But according to the traditional community of Siberut Island, Balubalu also means a collection of seven stars or Pleiades stars. The Sibalubalu tattoo motif in the order of the Mentawai indigenous people, shows that people who use it are good at maintaining physical health and well-being. The position of Sikerei is a very important part in an activity of punen or pulaijat and lia as a ritual ceremony.

\section{CONCLUSION}

In this research the writer does analysis on the Sibalubalu tattoo in social status of Mentawai culture, but this research focuses in Taileleu village. Here, the writer conclution that:

1. Sibalubalu tattoo is one part of the Mentawai tattoo motif that has the highest position among other Mentawai tattoo motifs

2. In the Taileleu area Sibalubalu tattoos are not located on the top of the shoulder, but are located on the arms and legs between the titi rere, which includes the silioi motif on the ankles and calves, and above the silioi motif there is a muriok sara motif up to the back

3. Sibalubalu as a symbol of health, said health because Sibalubalu is only used by Sikerei where Sikerei is a remedy for sick people in the Mentawai Islands, especially in Taileleu village.

4. Sibalubalu tattoo is the rank of the Sikerei in the Taileleu village, but the placement of Sibalubalu is not the same between men and women. In order for the nature of women as human survival not to be considered low, Sibalubalu is placed on the shoulders.

\section{The function of Sikerei tattoo}

The last point of this analysis is the function of Sikerei tattoo in Mentawai Island, especially in Taileleu village.

Evidence of a person's skills within the scope of the Mentawai indigenous community, is characterized by the existence of a variety of certain tattoos on the body, to explain the validity that the user of the tattoo is an expert in his field. The function of the Sibalubalu tattoo, as the identity of the profession of shaman. The motif is located at the base of the arm (shoulder).

The function of Sibalubalu tattoos is as a sign of recognition is the embodiment of their origin. It means to show origins and to recognize the territory. The function of the tattoo is the same as the peculiarity of the familiar sign which distinguishes the valleys where they live, as well as their respective dialects. The same thing was explained by Schefold (1991) explaining that each valley has its own dialect. In addition, there are often different, or distinctive fashion patterns and tattoo patterns.

5. In Taileleu village, is not only men who have known signs through tattoos, but also women. However, in the village of Taileleu the motives for identifying women are not as many as men have in their type.

This thesis is the early achievement that still needs to be develoved and continued with more careful study, especially in terms of the research in the field of Sibalubalu tattoo. The development and presentation of material in this thesis has not be able to delivery maximum result as expected. The material presented in this thesis, there are still shortcomings which need to be refined. Therefore, it is expected to follow student Department of English in order to perform the analysis further study more about Sibalubalu tattoo in Mentawai, especially in Taileleu village. In addition, student are also expected to English Literature Department in order to improve linguistic research so that eventually our result are very useful for those who need them. 


\section{Bibliography}

Abrams. M. H. and Harpham G. G. 2009. A Glossary of Literary Terms. London: Wadsworth

Barthes. Roland. 1992. The Structuralist Activity. Evanston: Northwestern University Press

Cohen and Shire, 1998. A Theoretical Analysis of Narrative Fiction. New York: Prentice Hall, Inc

Fainuddin Nuri (2004). Dekonstruktif Drama King Lear Karya William Shakespeares.Retrievedfromhttp://eprints.ua d.ac.id/2399/1/Bahastra_XVII_PAS.pdf . accessed on December $24^{\text {th, }} 2017$ at 03 : 43AM

Freud, Sigmund. 1956. Theory Pyschoanalytic. Jakarta : Yayasan pustaka Obor Indonesia

Hudson. 1997. An Introduction to the Study of Literature. London : Barnes Noble

Mardaly, 1999. Metode Suatu Pendekatan Prposal. Jakarta : Bumi Aksara

Pradopo. Rahmat Djoko. 2001. Metodologi Penelitian Sastra.Yogjakarta: Hanindita Ghasa Widia
Ratna, Nyoman Khuta. 2004. Teori, Metode, dan Teknik Penelitian Sastra dari Strukturalisme Hingga Postrukturalisme Persektif Wacana Naratif. Yogjakarta : Pustaka Pelajar

Robert Silhol. 2012. Unconscious Ambiguities in King Lear.Retrieved from http://psyartjournal.com/article/show/silholu nconscious_ambiguities_in_king_lear. accessed on December $24^{\text {th }} 2017$ at $04: 23$ $\mathrm{AM}$

Rogers, C. 1951. Client-centered therapy: Its current practice, implications and theory. London: Constable

Rogers, C. 1959. A theory of therapy, personality and interpersonal relationships as developed in the client-centered framework. In (ed.) S. Koch, Psychology: A study of a science. Vol. 3: Formulations of the person and the social context. New York: McGraw Hill.

Shakespeare, William. 1603. King Lear. London : Nabaniel Butter

Sumarjono. 1997. Penelitian Sastra. Jakarta : Balai Pustaka. 